\title{
Bioethics and the Hypothesis of Extended Health
}

\author{
by Nicolae Morar and Joshua A. Skorburg \\ Kennedy Institute of Ethics Journal
}

(Forthcoming)

\section{Introduction}

Dominant views about the nature of health and disease in bioethics and the philosophy of medicine have presumed the existence of a fixed, stable, individual organism as the bearer of health and disease states, and as such, the appropriate target of medical therapy and ethical concern. However, recent developments in microbial biology (Turnbaugh \& al 2007; Gordon \& Klaenhammer 2011; The Human Microbiome Project Consortium 2012; Grice \& Segre 2012; Blaser 2014; Knight 2015; Relman 2015), neuroscience (Kim \& Johnson 2010; Maravita \& Iriki 2004), the philosophy of cognitive science (Clark \& Chalmers 1998; Clark 2007a, 2007b; Sterelny 2010; Hutchins 2010), and social and personality psychology (Ickes, Snyder, \& Garcia 1997; Drigotas, Rusbult, Wieselquist, \& Whitton 1999; Fitzsimmons, Finkel, \& van Dellen, 2015), have produced a novel understanding of the individual and its fluid boundaries. Drawing on converging evidence from these disciplines, and following recent research in public health (Atlas 2012; Mackenzie \& al. 2013; Horton \& al. 2014), we argue that certain features of our biological and social environment can be so tightly integrated as to constitute a unit of care extending beyond the intuitive boundaries of skin and skull.

This paper lays the groundwork for a research program in extended health. Drawing from work in microbiology and social and personality psychology, we develop and defend the Hypothesis of Extended Health (HEH), which denies the claim that health and disease states are predicated solely on the internal functioning of an organism. We contend that this view has profound and wide-

\footnotetext{
1 Author names are listed in alphabetical order, which reflects equal contribution to the authorship of the article.
} 
ranging clinical implications. Namely, that the targets of medical invention and ethical concern are wider and more diverse than usually assumed. For example, HEH proposes that in certain cases of autoimmune illness, we cannot only consider the weakening of the internal functioning of the immune system, but we must also consider the extent to which such conditions are a function of dysbiosis - an imbalance in the diverse microbial communities inhabiting our body. Our ethical concerns regarding certain genetic interventions should not be limited to our germline, but should also integrate our second microbial genome (Rhodes, Gligorov, \& Schwab 2013). Similarly, in line with recent research in social and personality psychology, HEH proposes that health-relevant goal behavior might be more effectively regulated by close others - spouses, parents, friends, etc. - than by internal acts of sheer willpower.

While we will focus here on these two kinds of cases, we contend that HEH provides the conceptual resources to critically examine how theories of individuality influence clinical intervention strategies across a wide variety of health-relevant domains. Our central claim is that the individual - as the bearer of health and disease states - sometimes extends to include tightly integrated features of the biological and social environment. There is thus significant work to be done with respect to the bioethical implications of these extended sites of medical intervention.

Here is the plan for the paper. In Section 1, we provide a brief summary of the dominant conceptions of health and disease, showing how both naturalist and normativist views share an underlying commitment to internalism and individualism, in spite of their diametrically opposed conclusions about the status of health and disease concepts. In Section 2, we gather converging evidence from the biological and psychological sciences which challenges the default and intuitive view of individuals identified in Section $1 .{ }^{2}$ We then consider the One Health proposal, a recent

\footnotetext{
2 The 'line drawing problem' in philosophy of medicine has been recently the topic of an edited issue of the Journal of Medicine and Philosophy (Walker \& Rogers 2017). And, while a number of authors have questioned the dysfunction account for defining disease (Doust, Walker, Rogers 2017; Rogers \& Walker 2017), their arguments have focused
} 
development in the public health and bioethics literatures that acts as a counter to overly individualistic views of health and disease. In Section 3, we argue that while the One Health proposal is conceptually attractive in some respects, it may ultimately fail to produce reliable and practicable guidance for therapeutic interventions because it extends the relevant causal web beyond the epistemic and interventionist limits of medical practitioners. After formulating and responding to some potential objections, we then articulate and defend the Hypothesis of Extended Health (HEH) which occupies a centrist position between narrow individualism and nebulous externalism about the bearers of health and disease states. HEH thus highlights the possibility for new sites of therapeutic intervention and bioethical concern. We conclude by identifying future directions for a program of extended/ecological bioethics (Morar \& Skorburg 2016).

\section{Section 1: Individualism in the Dominant Views of Health and disease}

Here, we briefly highlight central features of the debates about the concepts of health and disease. We will not make yet another attempt to settle the naturalism vs. normativism debate. Instead, we summarize the debate with an eye toward identifying an unacknowledged common denominator between these competing views, namely an unreflective commitment to the individual buman organism as the bearer of health and disease states.

\subsection{Naturalism and Individualism}

The locus classicus of the naturalist view of health and disease concepts is Christopher Boorse's (1977) article "Health as a theoretical concept." Therein, Boorse famously argues that "disease judgments are value-neutral," and "their recognition is a matter of natural science, not

primarily on the definition of the boundaries of the concept itself while remaining committed to a narrow conception of the individual organism as the bearer of such states. 
evaluative decision" (pp. 542-43). Such claims are the heart of naturalism about health and disease concepts. Our aim is not to evaluate the (de)merits of this position, per se, but rather to call attention to the implicit assumptions about the nature of the bearers of these health and disease states. For example, the first feature in Boorse's (1975, p. 61) distinction between disease and illness is that the former is only an instance of the latter if "it is serious enough to be incapacitating, and therefore is undesirable for its bearer." While much ink has been spilled about the nature of this undesirability and the kinds of interventions it enjoins (or doesn't), the question of what, precisely, the bearer is, has received scant attention.

A standard argumentative move for naturalists about health and disease concepts is to link medical practice with natural science. Thus, Boorse says things like, "I shall assume that the idea of health ought to be analyzed by reference to physiological medicine alone" (1975, p. 49-50), and "the classification of human states as healthy or diseased is an objective matter, to be read off the biological facts of nature without need of value judgments (1997, p. 4). Because Boorse's arguments often hinge on his account of biological function and statistical normality (hence, his avowal of the term "biostatistical theory"), the default assumption is that the bearers of these health and disease states would be the paradigmatic biological individuals: organisms. Indeed, in Boorse (1997; see also 2014) the term "individual" nearly always occurs in the context of "individual survival and reproduction." This identification of "organism" with "individual" is easy and intuitive. So much so it often goes without explicit acknowledgement. It is precisely this assumption that is at the center of the default view for naturalists that organisms qua individuals are the bearers of health, illness, and disease.

We contend that, in the absence of any qualification, the identification of "organism" with "individual" is empirically inadequate and theoretically unattractive. In Section 2, we will show how recent work in microbiology poses difficult challenges for any intuitive account of organisms as 
individuals. But first, we will show how normativism about health and disease concepts similarly adopts default individualism.

\section{Section 1.2 Normativism and Individualism}

The normativist, unlike the naturalist, is keen to point out that a proper analysis of health and disease cannot be achieved without distinguishing between the physiological state of a certain condition (and whether it truly represents a deviation from a certain biological norm) and the ways in which a patient experiences (or not) this condition as something to be avoided, as an illness, along with the social norms that carve out her lived experience. There could be physiological dysfunctions that do not necessarily lead to undesirable conditions, and are rather considered healthy states. As Ereshefsky $(2009,223)$ points out, if a brain lesion caused gourmet behavior (such as developing a discerning palate), it is unclear that this dysfunction should be classified as a disease.

Thinking of health and disease in terms of normality and abnormality not only brackets important normative aspects that are embedded in what constitutes an undesirable condition, but it also assumes that physiological descriptions have an ontological and epistemic primacy over and above other factors, including social and cultural factors (Margolis, 1976; Engelhardt 1975, 1976; Goosens 1980). Defenders of normativism often deploy an argument about the case of homosexuality, which - until recently - has been labeled as a disease. Not only are they showing naturalists that medical knowledge cannot justify this label, but they point out that changes in values, especially social values, explain the removal of homosexuality in 1986 from the Diagnostic and Statistical Manual of Mental Disorders.

Nonetheless, the emphasis on the role of social values in health and disease ascriptions does not deter normativists from claiming that the proper unit of ascription is still the individual human being. Engelhardt, for example, notes, "there is an emphasis upon the individual, not the disease, as 
the reality in the illness" $(1975,131)$. What normativists challenge is the objective nature of naturalist descriptions of disease (or whether a disease can exit independently of diseased organisms), but not the unitary nature of the bearer of such states. There could be, Engelhardt (1975) claims, a disease without bearer, but "whenever there is a bearer it is still an individual" (p. 33; see also Engelhardt, 1976, 266).

The focus on individual organisms as the proper locus of health and disease ascriptions is not just the normativist response to some supposed standard of epistemic adequacy in medicine, but also a genuine concern as to what the unit of treatment and the unit of value should in medical practice. Engelhardt emphasizes that even in cases of schizophrenia or congestive heart failure, the focus is not just to restore certain physiological functions, but also to secure "the autonomy of the individual from a particular class of restrictions" $(1975,139)$. Medicine, after all, treats individuals (Goosens 1980, 107). More importantly, it treats individual patients who can ultimately be benefited or harmed by certain procedures and whose well-being should be at center of the medical practice. Consequently, "accounts that define health in terms of comparison to others (e.g. by normality) fail to allot supremacy to the individual" (Goosens 1980, 113) and fail to fully appreciate the individual as the ultimate unit of care and of bioethical concern.

In this section, we showed how even diametrically opposed views of health and disease (naturalism and normativism) still converge on the view that the individual organism is the bearer of these health and disease states. In the next section, we will examine how recent research in microbiology and social and personality psychology has challenged the empirical adequacy of this kind of individualism. 


\section{Section 2: Anti-individualism in Biology and Psychology}

In this section, we marshal resources from the biological and psychological sciences which calls into question the implicit view of individuality assumed in the aforementioned debates on health and disease. First, we show how the explosion of research on the human microbiome undermines traditional organism concepts built upon genetic homogeneity or intrinsic function (Section 2.1). Next, we turn to the psychological literature on goal pursuit to show how selfregulatory processes similarly cross-cut the boundary between agent and environment (Section 2.2).

\section{Section 2.1 The Microbial Challenge to Biological Individuality}

We have become increasingly aware that human organisms are complex ecological systems harboring a significant number of microorganisms, which directly participate in our physiology and have important influences on our psychology. ${ }^{3}$ Microbial biologists have noted for quite some time that an entire cohort of microbes lives on and inside of our bodies (e.g., Rosebury 1969, see also Postgate 2000). However, the magnitude of the interactions and the biochemical intimacy of these symbiont organisms has only recently begun to be fully appreciated, due to our ability to take a census of the species living in our biological neighborhood and to analyze the community composition of those microbial assemblages.

Carl Woese and Norman Pace's pioneering work has helped us to understand not only that specific genes could be used to identify microbial species (Woese \& Fox 1977), but also that by cloning entire samples of DNA, researchers could access $16 \mathrm{~S}$ rRNA sequences that could not be cultured in the laboratory (an approach known today as DNA shotgun sequencing; Pace \& al. 1986). Subsequently, some of the first human microbiome studies focused on the microorganisms living in the oral cavity (Scannapieco 1994), then in our gut, and in all the other niches of our bodies that they

\footnotetext{
${ }^{3}$ In fact, this ecological perspective probably holds for any animal or plant (McFall-Ngai et al. 2013).
} 
could successfully occupy. The emerging consensus is that human organisms are made of as many human cells as microbial symbionts (Sender, Fuchs, \& Milo 2016). ${ }^{4}$

The trillions of microbes present in our guts are doing us a great service by making available to our bodies certain polysaccharides that human enzymes alone could not metabolize. A classic example is the Hehemann et al. (2010) finding that Japanese guts seem particularly adapted for sushi (see also Schenkman 2010). A marine bacteria living on red algae and seaweed, Zobellia galactanivorans, has evolved to efficiently degrade algal cell walls. Unlike the Western diet, the Japanese diet consistently includes seaweed wrapping for sushi and, thus, the enzyme-coding gene has had the chance in the stomach environment to be horizontally transferred from this marine bacterium to another microorganism living in the gut - the Bacteriodes plebeius (Sonnenburg 2010). Because of this, the Japanese gut can uniquely derive energy from a certain algae-based diet. Crucially, this specific feature of digestion has little to do with human genetics. Thus, there is a strong sense in which the microbiome extends the physiological process of digestion and makes available to the human body a series of calories that the host could not have otherwise extracted by its own internal means.

Additionally, studies on obesity have not only confirmed the central role of our gut microbiota in our caloric intake, but have also shown the tight connection between our gut inhabitants, our diet, and certain physiological states, such that obesity cannot be simply reduced to abnormal host genetics or poor diet. Instead, the microbiome must be taken into consideration (Turnbaugh \& al. 2009). Recent studies on the role of indoles produced by commensal bacteria showed also that these small molecules can induce in aged animals (such as mice) gene expression profiles mimicking the ones observed in the young, thus extending the mice's fecundity and reproductive span, and their lifespan overall (Sonowal \& al. 2017).

\footnotetext{
${ }^{4}$ Human organisms consist of about 40 trillion human cells and the microbial cells constituting our microbiome is around 100 trillion cells, thus the ratio of 2.5 to 1 seems the most accurate one today (Ravel et. al. 2014). More recent studies promote an even lower ratio -1 to 1 (Sender, Fuchs, \& Milo 2016).
} 
Microbial biologists have reached similar conclusions about the role of microorganisms in our metabolism, in the renewal of gut epithelial cells, in the proper development and training of our immune system, and even in human behavior and psychology (Turnbaugh \& al. 2007).

Another exciting line of research explores how our microbiome also has an important effect on our brains by directly influencing our behavior through the gut-brain-axis (Rhee \& al 2009; Collins, Surette, \& Bercik 2012; Heijtz \& al. 2011). Through neural, hormonal, and immunological pathways, the enteric microbiome communicates bi-directionally with the brain, influencing both the function of our central nervous systems (CNS) and vice-versa, with the CNS modulating microbial composition through effects on the gastrointestinal tract. This bidirectional communication is particularly well observed in stress-related research on mice, and the implications of this research are relevant for psychiatric disorders such as anxiety, depression, and even autism.

For example, germ free animals display reduced anxiety in 'plus maze' or 'light-dark box' tests used to measure anxiety relevant behavior (Neufeld \& al. 2010). Gnotobiotic mice also show a deficit in non-spatial and working memory tasks by failing to easily recognize novel objects or modification in a T-maze test (Gareau \& al. 2010). Moreover, cognitive and behavioral effects are also observed in cases of bacterial infections (Bercik \& al. 2010) or in studies on probiotics both in rats and humans (Arseneault-Breard 2012; Messaoudi \& al. 2011). This growing body of evidence has led a number of microbial biologists and neuroscientists not only to posit the gut-brain axis as a way of understanding the relationship between our microbiome and our psychology, but also to highlight the extent to which our gut-microbiota affects the functioning our central nervous system. Crucially, this opens the possibility for future microbiota-related therapeutics in cases of psychiatric disorders (Cryan \& Dinan 2012).

In addition to these therapeutic possibilities, the vast body of research on the human microbiome has important bearing on the debates about health and disease states. We contend that 
insofar as naturalist and normativist (or hybrid, for that matter) theories of health and disease unreflectively assume an intuitive view of individual-as-organism, they will be subject to charges of empirical inadequacy. After all, to which biological organisms do such views refer? If only to the 'organism' containing human DNA, then these theories will be, at best, incomplete (and at worst, false) with respect to the questions about digestive, immunological, and psychological functioning considered here.

\section{Section 2.2 The Transactive Challenge to Psychological Individuality}

In the previous section, we surveyed research in microbiology which called into question simple-minded views of biological individuality. Some of this work suggested that there are important connections between the gut and brain, and that microbial functioning is linked with psychological processes. Taking this connection as a cue, the present section explores how some recent work in social and personality psychology similarly calls into question the dominant (and often implicit) view of psychological individuality. By the end of this section, we hope to have established that research from the biological and psychological sciences converge on certain criticisms of the default and intuitive view of the individual - precisely the view that is assumed in the debates about the concepts of health and disease.

Consider one of the most famous experiments in psychology. A four-year-old child is seated alone at a table and an experimenter sets a single marshmallow in front them. The experimenter then tells the child they can eat the one marshmallow now, but if they wait, (usually around 15 minutes), then they can have two. Remarkably, children's ability to delay gratification - that is, resist the temptation to eat one now - predicts significant life outcomes up to 30 years later. For example, Schlam et al. (2013) report that longer delay of gratification at four years-old predicts Body Mass Index, such that each additional minute of delay was associated with a 0.2 -point reduction in BMI in 
adulthood. The connections between this research and health-relevant domains such as obesity and addiction are clear. Indeed, as Mann, DeRidder, \& Fujita (2013, p. 494) note, health is a "prototypical and central domain" in which to study social psychological theories of self-regulation. In addition to these health outcomes, Mischel, Shoda, \& Rodriguez (1989) also report that children who delayed longer as preschoolers were rated in adolescence as significantly more attentive, focused, competent, planful, intelligent, and able to deal with frustration, than low delayers. Moreover, higher verbal and quantitative SAT scores were significantly correlated with longer delay in preschool.

No doubt, the results are impressive, and indeed, it is hard to overstate the influence of this research. However, recent work on self-regulation has called attention to a peculiar feature of this research paradigm:

From the perspective of the most well-known and well-established models in the psychological literature, people either succeed or fail at self-regulation as individuals, toiling in isolation toward goal achievement. From the four year-olds in the famous delay of gratification studies (Mischel, 1974) who sit by themselves trying not to eat a marshmallow to the hungry participants in the seminal study of self-regulatory depletion who sit by themselves eating radishes instead of cookies (Baumeister, Bratslavsky, Muraven, \& Tice, 1998), psychological studies of self-regulation, and the theories that have inspired those studies, have predominantly focused on individuals pursing their goals alone (Finkel, Fitzsimmons, \& van Dellen, forthcoming, p. 22).

In a series of papers, Gráinne Fitzsimmons and colleagues have developed a new model of goal pursuit and self-regulation that calls into question the adequacy of this dominant, individualist framework. Their alternative framework - transactive goal dynamics - is introduced as follows:

the theory [of transactive goal dynamics] depicts relationship partners as exerting such a great deal of mutual influence in each other's goals, pursuits, and outcomes that the partners' self-regulatory systems become inextricably linked, part of a complex and messy web of interdependence. Ultimately, we suggest that relationship partners are best conceptualized not as mostly independent goal pursuers who occasionally influence each other, but instead, as interdependent subparts of one self-regulating system (Fitzsimmons, Finkel, \& van Dellen, 2015, p. 648, emphasis ours).

Part of the motivation for this view is that while the classic experimental paradigms used to study self-regulation often yield clean, readily interpretable results, they do not necessarily reflect the ways 
most people go about trying to achieve health-related goals outside of the lab. It is not just that Pat has a goal to lose weight. It is also that Pat's partner Jordan is training for a marathon. So, when they go grocery shopping together, each can help the other achieve their goals by, say, purchasing healthy food. Pat trying to lose weight does not happen in a social vacuum, independent of certain social and material conditions. ${ }^{5}$ After all, think about how well things would go over if Jordan was instead training for an eating contest.

It is crucial to see, however, that leveraging a criticism against the dominant individualist views of self-regulation amounts to more than a criticism of ecological validity. The positive claim is that social processes play an important role in self-regulation that has been underappreciated by researchers. Put another way, a narrow focus on intra-individual processes (like willpower: Pat trying to resist the temptation to eat the cream cheese brownie) often renders invisible inter-individual processes (like affirmation: Jordan's subtle nod of acknowledgment when Pat passes up the cream cheese brownie) that may turn out to be highly relevant to understanding how and why people achieve their goals (or fail to).

Because of their proximity, relationship partners can exert unique, persistent, and effective influence on one another. So much so, that their goals can become interdependent and the relationship or the dyad (rather than each individual partner), is more accurately characterized as the bearer of the self-regulatory processes. But why bother with a complicated, messy framework positing higher-order individuals when a simpler, more traditional model is widely available? Or, as Finkel, Fitzsimmons, \& van Dellen put it, "why must we consider a challenge to the pervasive (if implicit) assumption that goal-related processes predominantly reside within a single individual?” The answer, they contend, is that:

\footnotetext{
${ }^{5}$ Public health researchers and ethicists have extensively argued for a view of health that extends beyond human physiology to include also its social and material determinants (Amick \& al. 1995; Marmot 1998, 2005; Ruger 2004; Daniels 2007).
} 
If the goal of self-regulation research is to develop models of goal-relevant processes that emerge within prototypical laboratory experiments-those in which individuals are, for example, seated alone at a table with a marshmallow on it or at a computer screen with tempting images on it - then the individual unit of analysis may well be optimal. If, in contrast, self-regulation researchers want to understand how people set, pursue, and achieve goals in their everyday lives, then a predominant focus on individual-level processes is likely to yield an incomplete, perhaps even inaccurate, understanding of goal dynamics. Consequently, we argue, any conceptual model seeking to capture such dynamics must address topics like how pervasively people set and pursue goals for others and have those others set and pursue goals for them, and the circumstances under which social processes promote versus undermine goal achievement. (forthcoming, p. 3, emphasis ours).

What is striking in the present context is the emphasis on how traditional models construe the relevant self-regulatory processes as "residing within the individual" and how such a view yields, at best, an incomplete and, at worst, an inaccurate account of self-regulation and goal pursuit. This insight is at the heart of HEH (which will be developed in more detail below): construing health and disease as residing solely within the individual yields, at best, an incomplete and, at worst, an inaccurate picture. And in the same way an overly individualistic approach to self-regulation may obscure crucial explanatory and predictive resources, so too does an overly individualistic approach to health and disease obscure possible sites for medical intervention.

In the context of self-regulation and goal pursuit (as well as health and disease), the claim here is decidedly not that intrapersonal processes are irrelevant. Instead, the claim is that a blinkered focus on internal processes alone yields an incomplete account, and perhaps one that downplays or ignores interpersonal processes that turn out to be crucial for goal achievement (or health and disease). It is not that internal willpower does not matter at all. It is rather that a myopic focus on willpower - at the expense of the unique interpersonal dynamics in close relationships - will render invisible features of self-regulation that might turn out to be crucial for understanding whether and how people achieve their health relevant goals.

To sum up, we have developed a two-pronged argument against individualism, showing how recent evidence from the biological and psychological sciences suggests the empirical inadequacy of 
the largely unreflective notion of individuality in the debates of health and disease concepts.

However, we are far from the first to recognize the inadequacy of individualism, broadly construed.

\section{Section 3: The One Health Paradigm}

Here, we consider a developing paradigm of health and disease that could potentially accommodate some of the evidence presented in Section 2. In Section 3.1 we briefly summarize the One Health view, which, at first blush, looks like a promising candidate given that it proposes a bolistic conception of health and disease that extends beyond the traditional individual in order to account for the intricate links between humans, wildlife, and environmental health. In Section 3.2, we argue that despite this initial promise, the One Health view suffers from deep problems of practicability. We consider also two potential objections to our line of criticism against the One Health Paradigm, and, then in Section 3.3, we formulate some criteria for the demarcation of extended biological and psychological systems. In Section 3.4, we provide our positive account of extended health in response to the shortcomings faced by the One Health paradigm. We do this by incorporating via analogy some critical tools from the extended mind debate.

\section{Section 3.1: What is One Health?}

There is growing recognition among medical practitioners, infectious disease physicians, public health officials, and bioethicists that human health is best understood - and also best therapeutically supported - when it simultaneously addresses animal, human, and ecological health (One Health Initiative Task Force 2008; Atlas \& al. 2010; Coker \& al. 2011; Kakkar \& Abbas 2011; Dantas-Torres \& al. 2012; Atlas 2012; Centers for Disease Control and Prevention 2013; Shomaker, Green, \& Yandow 2013; Mackenzie \& al. 2013; Wolf 2014; Hinchliffe 2014; Rock \& Degeling 2014; Capps \& Lenderman 2014; Zinsstag \& al. 2011, 2015; Demaio \& Rockström 2015; Degeling \& al. 
2016; Lee 2017). The boundaries between these various levels of physiological and biological organization, as the argument goes, are arbitrary. As pathologist Rudolf Virchow notes, "between animal and human medicine there are no dividing lines - nor should there be" (Atlas \& al. 2010, 385). This is the slogan of the One Health paradigm.

This interdisciplinary framework has emerged as a way of responding to and pushing back against traditionally siloed domains of medicine. In this setting, hyper compartmentalization of knowledge has led to a significant deficit of communication and integration of results coming from, for example, veterinary medicine and environmental management. As numerous cases of pandemics or outbreaks have shown, human health is intimately connected with other non-human animals and with the environment writ large. Hence, any medical practitioner that reduces their conception of health and disease to the internal normal functioning of an individual organism fails to acknowledge the convergence of those domains of knowledge, and the need for a holistic health framework in order to prevent, to control, and to treat future diseases.

The proponents of the One Health paradigm are committed to two core beliefs that seem to ground a new ontology about interspecies health concerns (Craddock \& Hinchliffe, 2014). First, they consider that the world, our 'one world' (Colizza \& Vespignani 2010), is more like a 'global village'. Given the global economic conditions, distances are shrinking and health effects that are realized on one continent are rapidly reverberating globally (think of the recent Ebola crisis, from its zoonotic aspect (Leroy \& al. 2005) to its process of transmission (Bausch \& al .2007), to its global outbreak (Kaira \& al. 2014)). This belief highlights the extent to which human, animal, and environmental conditions fostering livelihood are inextricably linked, up to the point that their own intertwined ecologies break down any meaningful boundaries between individuals or species. After all, microorganisms and viruses are only minimally committed to a single type of host. This profound sense of interconnection is not only considered self-evident by One Health practitioners, but it also sets 
up a stronger demand on both medical personnel and on Academic Health Centers to move away from siloed domains of knowledge and to integrate diverse expertise from microbial biology, to veterinary and human medicine, to ecological management (Atlas \& al. 2010, Atlas 2012, Shoemaker \& al. 2013). The interconnectedness of our world requires a multi-factorial repose regarding the evolution of human-animal-pathogen interaction.

The second core belief of One Health is that the nature of the response to complex organismal interactions cannot but integrate a greater number of disciplines and approaches, especially in cases of health crises. Consider the case of the spreading of the West Nile virus in New York City in 1999. New York residents observed the supposedly unrelated deaths of crows and exotic birds from the Bronx zoo, and in parallel with all of this, eight cases of meningoencephalitis that had been reported by public health officials. Once infectious disease scientists isolated the virus from various tissue specimens from dead birds from the Bronx zoo, they were not only able to realize the virus' mode of transmission (e.g. mosquito vectors) but they also understood the rapid increase in human infections (51 human cases were reported, 7 died and 10 developed paralysis; Shoemaker \& al. 2013, 49).

This case brought forward a number health-related lessons. At that time, a number of scientists called for dismantling the divisions between medical and veterinary practices (Nash \& al. 2000) by defending the need for stronger training in comparative medicine in Academic Health Centers (Saunders, 2000; Shomaker, Green, \& Yandow 2013). These calls for greater integration require a re-evaluation of the concept of zoonoses (Atlas \& al. 2010) and a certain scientific appreciation of the fact that microorganisms are not only moving from one species to the other, but that microbial biology opens the possibility for understanding the emergence of infectious diseases, their molecular signature, their level of virulence, and ultimately their evolutionary pathways. The integration of all these aspects of medicine, from infectious diseases, to microbial biology, and to 
veterinary and human health, would have supported a more holistic response to such viral based zoonosis.

Microbial biology, especially today through the lens of research initiatives like the Human Microbiome, opens also a new understanding of the mutualistic (Rosenberg \& Zilber-Rosenberg 2016) and the ecosystem-like (Costello \& al. 2012) nature of our biochemistry. For this reason, One Health proponents have claimed that microbiology could play the role of "a unifying discipline that connects health among humans, animals, and the environment” (Atlas \& al. 2010, 383).

\section{Section 3.2: Challenges to the 'One Health' Paradigm}

We argued that many of the views in Section 1 were deficient due to narrowness. Here, we contend that the One Health view is also deficient - this time, due to excess. Our claim is that while One Health certainly offers a corrective to overly individualistic views of health and disease, it ultimately lets the pendulum swing too far. ${ }^{6}$ The result is a kind of externalism that is too permissive to be of use on a clinical scale and in a clinical context. To develop this criticism, we turn to an analogous proposal in the philosophy of cognitive science: the hypotheses of extended mind and cognition (Clark \& Chalmers 1998).

We have all heard it by now: "I couldn't tell you the last time I had to memorize a phone number, they're all just stored in my phone now.” With this phenomenon in mind, Andy Clark and David Chalmers asked, "where exactly does the mind stop and the rest of the world begin?" They

\footnotetext{
${ }^{6}$ It should be noted, if only in passing, that others have staked out positions between what we are here calling strict individualism and nebulous externalism. For example, Arah (2009) argues that "health is not entirely individual; it is relative to the individual's context, which in turn is fashioned out of the interactions that exist between members of any defined collective whose health (read: population health) is defined by the health and context of its members" (p. 238). We endorse the anti-individualist spirit of this claim. But despite arguing for the dynamic and causal force of context, nowhere does Arah call into question the nature of individuals qua bearers of health and disease states, which is our primary focus here. Thus, we view this work, and related work in population ethics (e.g. Rose, 2001; May, Byonanebye, \& Meurer, 2017) and the metaphysics of health (e.g. McShane, 2004) as complementary to our own, but aimed at different targets and engaged with different literatures. Thanks to Sean Valles for helpful suggestions on this point.
} 
concluded, provocatively, that "if, as we confront some task, a part of the world," such as a

smartphone, "functions as a process which, were it done in the head, we would have no hesitation in recognizing as part of the cognitive process," such as recalling a phone number from biological memory, "then that part of the world is (so we claim) part of the cognitive process. Cognitive processes ain't (all) in the head!" (1998, p. 8).

The claim that smartphones thus extend our minds has been subject to vigorous debate since the publication of Clark \& Chalmers's article, and while we cannot possibly summarize that vast body of literature here (see Menary 2010 for an overview), we can point to an instructive analogy. In much the same way that the hypotheses of extended mind and cognition propose to expand the scope of cognitive science, so too does One Health propose to expand the scope of medical practice.

For present purposes, the most important connection between the extended mind and One Health, however, lies in an objection to the former, which we believe also applies in parallel to the latter. Arguments for the extended mind have faced the persistent charge of what Addams \& Aizawa (2010) call the coupling-constitution fallacy.

When Clark makes an object cognitive when it is connected to a cognitive agent, he is committing an instance of a coupling-constitution fallacy. This is the most common mistake that extended mind theorists make. The fallacious pattern is to draw attention to cases, real or imagined, in which some object or process is coupled in some fashion to some cognitive agent. From this, one slides to the conclusion that the object or process constitutes part of the agent's cognitive apparatus or cognitive processing. Yet coupling or connective relations are distinct from constitutive relations, and the fact that object or process $\mathrm{X}$ is coupled to object or process $\mathrm{Y}$ does not entail that $\mathrm{X}$ is part of $\mathrm{Y}$ (pp. 67-8).

The coupling constitution fallacy highlights the need for a principled set of criteria to distinguish mere coupling or connectivity from full-blown constitution. Without such criteria, an offshoot of the coupling-constitution charge looms large, and that is what Rupert (2004) first identified as the problem of "cognitive bloat". Rowlands (2013) - a proponent of extended cognition - puts the 
problem this way: "Once we permit such [extended cognitive] processes, where do we stop? Our conception of the cognitive will become too permissive, and we will be forced to admit into the category of the cognitive all sort sorts of structures and processes that clearly are not cognitive" (p. 86). When this line of criticism is adapted to debates about health and disease, it spells trouble for the One Health proposal.

The analogous objection would be this. If we permit constitutive connections among agents and their biological, social, political, economic, and ecological contexts as One Health specifies, where do we draw the line? If everything matters for health, then there is a sense in which nothing really matters. As Beever \& Morar (2017) point out, One Health's conception of health and disease runs the risk of becoming far too permissive and bloated. The analogous concern is that by extending health and disease too far, we will then be forced to admit all sorts of entities into the domain of medical practice that are clearly outside the scope of realistic, effective medical interventions. In much the same way proponents of extended cognition are faced with the problem of providing principled criteria for constitution to block the cognitive bloat objection, so too is One Health - in the absence of such principled criteria - left open to the potentially devastating charge of medical bloat. The specific worry is that by extending the constitutive components of health so far into the biological, social, and political environment, we will be left with a conception of health stretched so thin as to be impracticable from a clinical perspective.

In Section 3.3, in response to these concerns, we will formulate some candidate criteria for the demarcation of extended biological and psychological systems to set up our account of extended health in Section 3.4. But first, it is worthwhile to pause and take stock of the analogies (and also, disanalogies) of our argument so far.

One might object that a debate in the philosophy of cognitive science is orthogonal to issues in bioethics and the philosophy of medicine. After all, there are non-trivial differences between 
cognition and the practice of cognitive science on the one hand, and health and therapeutic practices, on the other. It might be further objected that the hypothesis of extended cognition is controversial, and if there are reasons to doubt its plausibility, then there will be reasons to doubt its connection and its relevance to issues about health and disease states. We will address each of these worries in turn.

First, we grant that there are important differences between the domains of cognition and health, and thus, we recognize that this analogy can take our argument only so far. However, for our purposes, we only need to show that debates in the former can help to illuminate novel and interesting features in the latter. We contend that the analogy is warranted on the grounds that much of the theorizing in the extended cognition literature can be unified by a broad appeal to antiindividualism (see Menary, 2010, p. 459; Cash, 2013, p. 61) which aims to expand the scope of cognitive scientific inquiry (see Clark, 2010, p. 64). The same holistic tendency is apparent in the One Health paradigm, not only in their fifth Manhattan principle, ${ }^{7}$ but also in the way in which practitioners think of how to conceive adequately of diseases linked to H1N1 influenza virus, to the SARS coronavirus, or the West Nile virus:

These diseases remind us that the health of humans, animals and ecosystems are interconnected, and that to better understand and respond rapidly to zoonotic diseases at the human-animal-environment interfaces requires coordinated, collaborative, multidisciplinary, and cross-sectoral approaches. This bolistic approach has been referred to as 'One Health', indicative of the commonality of human and animal medicine, and their connection to the environment." (MacKenzie \& al. 2013, v; emphasis ours).

Of course, there is not an identification between extended cognition and One Health, but because each research program takes as its foil a kind of narrow individualism and advocates for a more expansive vision, it seems likely that each could inform the other with respect to some core

\footnotetext{
7 "Devise adaptive, holistic and forward-looking approaches to the prevention, surveillance, monitoring, control and mitigation of emerging and resurging diseases that take the complex interconnections among species into full account" (Cook \& al. 2004)
} 
commitments. This is most apparent, we have tried to show, in the context of the objections (e.g. coupling-constitution and bloat) faced by each framework. Moreover, this broad appeal to antiindividualism potentially makes available a wide range of supporting evidence from allied approaches such as enactivism (e.g. Thompson, 2007) and developmental systems theory (e.g. Griffiths \& Gray, 1994), more on which below. ${ }^{8}$

Second, our argument for extended health is not exclusively hitched to the extended cognition bandwagon. While the plausibility of the latter would certainly help our case, what is central to our argument is not a particular formulation of extended cognition, but rather, the conceptual framework (what Clark \& Chalmers (1998) call "coupled systems") used to examine the various dependence relations between organisms and environments. In applying this framework to debates in bioethics and the philosophy of medicine, we avow a pluralistic approach which leaves open - indeed, welcomes - the possibility that an equally compelling case could be made by way of appeal to other broadly anti-individualist or anti-internalist programs such as enactivism or developmental systems theory. We have chosen the extended cognition framework because there are a number of fairly well worked out and nuanced distinctions in the literature (e.g. Rupert's (2009) hypothesis of embedded cognition; Sterelny's (2010) hypothesis of scaffolded cognition; Gallagher's (2013) socially extended mind, etc.). The fact that different theoretical frameworks could be used to deduce similar conclusions serves as compelling and converging evidence for our central claims about the bearers of health and disease states.

\footnotetext{
${ }^{8}$ We hasten to add that there is disagreement in the literature regarding the compatibility between extended and enactive views of cognition (see Rowlands, 2009; Di Paolo 2008). Nothing in our argument hinges on settling this debate, but we do think that each camp can potentially provide valuable resources to a robust conception of extended health. Thanks to an anonymous referee for pressing us on this point.
} 
Having formulated and responded to possible objections to our argument, we turn now to a discussion of some principled criteria for the demarcation of extended biological and psychological systems which will clear the way for our positive account of extended health.

\section{Section 3.3: Criteria for the Demarcation of Extended Systems}

So far, we have argued that classic conceptions of health and disease are overly narrow, empirically inadequate, and theoretically undesirable. We have also argued that One Health, perhaps the most developed alternative in the literature, is overly permissive, and as a result, clinically inert. What is needed, then, is an account of the bearers of health and disease which addresses the shortcomings of restrictive internalism (as we detailed in Section 2) without succumbing to a bloated, permissive externalism (as we detailed in Section 3.2). Drawing another analogy with the philosophy of cognitive science, here is how Edwin Hutchins (2010) puts the problem:

Everything is connected to everything else. Fortunately, not all connectivity is equally dense. The nonuniformity of connectivity makes science possible. Choosing the right boundaries for a unit of analysis is a central problem in every science and the basic approach to this problem has been in place for 2,000 years. Plato advised that one should 'carve nature at its joints' (Phaedrus 265d-266a). By this, Plato meant that we should place the boundaries of our units where connectivity is relatively low (pp. 705-6).

How, then, to carve the joints around the bearers of health and disease? We advocate for a pluralist approach, and we suspect there are many ways to do so. In the previous section, we developed our criticisms of One Health by way of an analogy with the extended mind and cognition research program. Here, we will draw from the same literature to formulate a response to this criticism. ${ }^{9}$ At

\footnotetext{
9 Again, we do not mean to imply that appeal to the extended cognition literature is the only way to accomplish this. However, we do contend that the versions of extended cognition advanced below - with their emphases on mutuality and reciprocity - are particularly well-equipped to account for the unique dynamics exhibited by symbiont microbes and romantic partners.

An anonymous reviewer has suggested that the enactivist paradigm may be a better resource than the extended paradigm. It is hard to see how some varieties of enactivism (such as sensorimotor or anti-representationalist enactivism) are linked with our central concerns here about the bearers of health and disease states. The autopoetic strand of enactivism (e.g. Varela, 1997; Di Paolo 2005) does seem promising in this regard, but the limitations of space prevent us
} 
the heart of the recent debate over extended minds are the kinds of questions raised by Hutchins.

Which criteria are used to determine when the components of a coupled system are merely coupled, and when the components are constitutive of an extended biological or cognitive system?

Though many proposals have been made in the extended mind literature to distinguish mere coupling from full constitution, (e.g., Clark \& Chalmers (1998); Wilson \& Clark (2009); Sterelny (2010); Sutton et al. (2010)) the most sophisticated efforts are probably Palermos's (2014) ongoing feedback loops criterion, Heersmink's (2015) dimensional analysis., and DeJeagher, Di Paolo, \& Gallagher's (2010) tripartite distinction between contextual factors, enabling conditions, and constitutive elements. Each can put us on the right path toward a balanced account of extended health.

To begin, Palermos explicitly formulates the ongoing feedback loops criterion in an effort to block the coupling-constitution and cognitive bloat worries. Borrowing terminology from Dynamical Systems Theory, Palermos writes:

(I)n cases where two nonautonomous systems mutually interact on the basis of feedback loops, there is an ongoing causal amalgam between the two units that disallows their decomposition into two separate systems on the basis of distinct inputs and outputs... The reason is that the way each component is affected is not exogenous to the component itself, and so cannot be properly thought of as its input. Likewise, the way each component affects the other is directly and synchronically related to the component to be affected and so cannot be properly conceptualized as output of the affecting component... We can call this the 'ongoing feedback loops' argument for the (ontological) postulation of coupled systems...In other words, ongoing mutual interdependence on the basis of feedback loops is the criterion by which we can judge whether two seemingly distinct systems constitute an overall system, consisting of both of them (Palermos, 2014, pp. 33-4).

Here and elsewhere (Carter \& Palermos, 2016), Palermos suggests that Tactile Visual Substitution Systems ${ }^{10}$ exemplify these ongoing feedback loops. Skorburg (2017) argues that the interpersonal

from pursuing this line in depth it deserves. Nevertheless, if an enactivist argument can be mounted in favor of our conception of extended health, this convergence would be a welcome development. Indeed, we hope such work will be pursued, and we can also imagine similar arguments being developed from the perspectives of developmental systems theory, extended phenotypes, and other allied approaches in the philosophy of biology.

10 For an overview of sensory substation interfaces, see Bach-y-Rita \& Kercel (2003). 
dynamics in close relationships, such as expectancy confirmation effects (Jones 1986) and various kinds of positive attributions (Martz \& al. 1998; Drigotas \& al. 1999), often similarly exhibit this structure of ongoing feedback loops. The relationship between the gut microbiome and the human organism similarly exemplifies these ongoing feedback loops (Backhed \& al. 2004). The point here is simply that insofar as two components of a coupled system (e.g., agent-smartphone, organismsymbionts, romantic relationship) can continually, reciprocally affect and be affected by one another, then there are grounds to posit an extended system comprising both components - that is, to carve out the bearers of health and disease states beyond the intuitive skin and skull boundaries.

Ongoing feedback loops, then, provide one general criterion for positing an extended system, and while Palermos's account provides a sound metaphysical basis for extended cognition claims, Heersmink (2015) helpfully builds on this view by developing a multi-dimensional framework which adds some fine-grained details:

This framework consists of the following dimensions: information flow, reliability, durability, trust, procedural transparency, informational transparency, individualization, and transformation. These dimensions are all matters of degree and jointly they constitute a multidimensional space in which situated cognitive systems can be located and have certain dimensional configurations. The higher a particular system scores on these dimensions, the deeper the functional integration is (Heersmink, 2015, p. 579).

Though we won't run through the whole analysis here, these dimensions provide a principled way to block the objection from cognitive (or medical) bloat. How do we know that a cognitive process like memory does not literally extend to include everything in our environment, such as shopping lists? Because such lists are, among other things, temporary and not particularly transformative of downstream cognitive processes. Further, there are no ongoing feedback loops between agent and list. How do we know that a meaningful definition of organism does not simply extend its boundary to include its entire surrounding environment? Because, among other things, there are no ongoing feedback loops between organisms and distal parts of the environment. It is not that $\mathrm{pH}$ of the soil or the microbes that live in it are wholly unrelated to the human organism, it is just that the degree 
of connection is too minimal to be constitutive. Similarly, it is not that someone in North Carolina is not connected to someone in Peru, but on average they are probably significantly less connected than with their romantic partner or neighbor, such that only their romantic partner or neighbor can potentially be considered as a constitutive part of their (psychological and social) individuality.

De Jaegher, Di Paolo, \& Gallagher (2010) have developed another particularly useful set of distinctions to capture the complexity of such phenomena by showing that there are contextual factors, enabling conditions, and constitutive elements at play in these situations. Contextual factors highlight the extent to which variation in any phenomenon is a function of unique and changing local factors. Enabling conditions show that in their absence, the relevant kinds of phenomena simply cannot obtain. Constitutive elements are the ones that produce a certain phenomenon, and thus without them, not only would a certain (metabolic, cognitive, etc.) event not occur but, but it would not be that specific kind of process (such as digestion or memory).

We believe that the arguments presented here by Palermos (2014), Heersmink (2015), and De Jaegher, Di Paolo, \& Gallagher (2010) are formidable responses to the coupling-constitution and cognitive bloat objections. That point needn't be settled here, however, as the real question is whether and how the criteria from the extended cognition literature bear on the debates about health and disease. We are now in a position to see what this looks like.

\section{Section 3.4: The Hypothesis of Extended Health}

In Section 2.1 we showed how hosts and symbiont microbes can be so tightly integrated as to form a new dynamic functional unit, supporting crucial processes like digestion and immune response. An intuitive view of biological individuality is inadequate to capture these interactions. In Section 2.2, we showed how partners' goals in close relationships can be so tightly integrated as to form a new dynamic functional unit, supporting crucial self-regulatory and motivational processes. 
An intuitive view of psychological individuality will be inadequate to capture these interactions. The Hypothesis of Extended Health thus proposes that the bearers of health and disease states are these dynamic functional units. In the balance of this section, we show how this formulation can capture the converging evidence from Section 2 while avoiding the shortcomings identified in Section 3.

The concept of dynamic functional units can be specified with respect to the criteria drawn from the extended cognition debate. That is, a dynamic functional unit qua bearer of health and disease states is characterized by features such as ongoing feedback loops. Where there are ongoing feedback loops, there are grounds for positing an extended system. As we have seen with symbiont microbes and romantic partners, these feedback loops need not be contained within the skinbag, as it were. Immune response can extend to our microbiome, and motivation can extend to include our romantic partners. We suggest that there is no reason - save internalist/individualist prejudice - that the bearers of health and disease, and hence, the targets of medical therapy need to be confined to the skinbag, either.

Crucially, by grounding our conception of dynamic functional units in the criteria from the extended cognition debate, we also have a strategy at our disposal to guard against the couplingconstitution and medical bloat objections that plagued One Health. From a clinical perspective, the dynamic functional unit can also be specified in terms of openness to reliable and efficacious intervention. In addition to the ongoing feedback loops and dimensional analyses, this reliability criterion suggests that the bearer of health and disease states can extend beyond the skin and skull, without sliding into an overwhelming and impracticable externalism. ${ }^{11}$ When formulated in this way, our view has profound clinical implications.

\footnotetext{
${ }^{11}$ For a related proposal, see Reich, Hansen, \& Link's (2016) discussion of fundamental cause theory and fundamental
} interventions. Thanks to Sean Valles for calling this to our attention. 
Imagine a clinician helping a patient fighting a Clostridium difficile colitis. Up until recently, the main (and only) therapeutic procedures entailed an antibiotic treatment either with Metronidazole, Vancomycin, or Fidaxomicin. In cases of damaged intestines, the procedure is even more invasive since it includes the surgical removal of the affected parts. However, patients could often either develop an antibiotic resistance or the $C$. diff infection could come back. The therapeutic failure or limitation in this case stems (in part) from considering that the relevant unit of treatment, or the bearer of disease, is the individual organism and not the dynamic functional unit that would also include symbionts. Recent advances in microbial biology and gastroenterology have invited us to think beyond the intuitive conceptions of the organism (e.g. genetic homogeneity), and to see the bacteria populating our guts as the appropriate site of therapeutic intervention. This lies behind the proposal made by a number of clinicians to use fecal microbiota transplantation as a form of therapy to C. diff infections (Borody \& Khoruts 2012; Kelly 2013; Kelly \& al. 2014; Gupta \& al. 2016) and to propose one of the first randomized, controlled, double-blind clinical trial in microbiota therapy (Kelly \& al. 2016). The success of this form of therapy is but one source of evidence that our old views about health and disease ought to be revised in order to integrate new sites of intervention as HEH specifies.

Or imagine a clinician developing interventions to target childhood obesity. To be sure, traditional internalist and individualist strategies targeting willpower, appetitive cues, and temptation might prove effective. But HEH can help to see additional, novel, interpersonal intervention strategies as well. For example, Best et al. (2016) show how, after family based therapy, parent-child dyads are strongly correlated with respect to outcomes like weight loss, weight maintenance, and fruit and vegetable consumption. They conclude that obesity treatments targeting the parent only might also turn out to be effective at producing weight loss in the untreated child. In the framework proposed here, we read these results as supporting the view that the parent-child dyad - rather than 
the parent and child individually - constitute a dynamic functional unit that is itself the bearer of the health and disease state. This conceptualization can help to reveal new pathways of influence, and hence, new intervention strategies (e.g., targeting the intake of energy-dense, nutrient-poor foods in the parent as a way to reduce intake in the child). Indeed, there is evidence that treating dyads (again, as opposed to the individuals therein) as a dynamic functional unit yields therapeutic benefits across a number of health-relevant domains including diabetes and blood glucose monitoring (Anderson et al. 1997; Berg et al., 2013), sleep apnea (Baron et al., 2011), arthritis (Hemphill et al. 2016), pain management (Wilson et al., 2017), and aging (Rauers, Riediger, Schmiedek, \& Lindenberger, 2011). ${ }^{12}$ Crucially, we are able to claim that health and disease can extend to include symbiont microbes, parents, or spouses without sliding into the claim that health must also extend to include the advertising industry, cultures of consumption, oppressive economic practices, etc. We do not mean to imply here that sometimes social and material conditions (e.g. economic access to whole series of primary health goods), or even certain environmental inputs (e.g. pollution), cannot be directly relevant for supporting (or undermining) health. We contend that one can recognize the importance of the environment, while seeking a more principled way to expand the boundaries of the units of care. So, interpersonal and interspecies processes can be the bearers of health and disease insofar as there are ongoing feedback loops between them and reliable pathways of intervention. Such feedback loops are clearly present in host-microbe and parental relationships, and clinicians can reliably intervene on such relationships. Feedback loops and reliable intervention sites are clearly less present in the relationship between individual agents and global economic structures.

$\mathrm{HEH}$, then, aims to carve the nature of individuals at their interventionist joints. If nature does not seem to respect the clean, intuitive, boundaries of skin, skull, and species for individuals, then there is no reason our concepts of health and disease should be beholden to such boundaries,

\footnotetext{
12 Thanks to Grainne Fitzsimons for calling these sources to our attention.
} 
either. Especially if such boundaries reduce the possibilities for future clinical interventions (for the human microbiome: Morar \& Bohannan, under review).

\section{Conclusion}

In this paper, we introduced the Hypothesis of Extended Health, which denies that the boundaries of the bearer of health and disease states are limited to skin and skull. We argued that our symbiont microbes and romantic partners extend our own physiology and psychology beyond the intuitive limits of the human organism. However, this hypothesis does not completely deny the utility of an internalist/functional account of health or of the One Health paradigm. Rather it stakes out a principled middle ground between single organs/organisms and global populations. We do not want to deny that in some cases, you really do just have to fix the internal functioning of the heart. Nor do want to deny that there are unique dynamics of pandemics and outbreaks that do involve distal parts of the environment (e.g. the Q fever outbreak in the Netherlands - Atlas \& al. 2010). However, we think there is a significant, important middle ground where there is much work to be done. This perspective, we hope, will open routes for a whole new range of new clinical intervention strategies in domains such as obesity and addiction.

Moreover, HEH suggests future directions that will support a different way of conceiving therapeutic interventions. To be sure, what we are proposing here is a hypothesis sensu stricto, which should be subjected to empirical tests and pragmatic verification. Regardless, we believe that there are conceptual benefits that stem from thinking about ourselves as dynamic functional units or as ecological systems. This framework opens the possibility for imagining different modes of medical intervention including, for example, psychological dyads, microbiota treatments, probiotics, or vaginal seeding in cases of C-section delivery (see Costello \& al. 2012). 
Moving away from a narrower conception of health and disease also offers us the opportunity to highlight new sites of ethical concern surrounding technological props or other organisms that we have reliably integrated into a wider conception of ourselves (Clark, 2017). This, in turn, challenges some core concepts in bioethics such as the self, autonomy, and informed consent (see Beever and Morar 2016). But it also supports engagement with new traditions such as feminist philosophy (e.g. relational autonomy; see, MacKenzie \& Stoljar 2000), and will ultimately be allied with the various social and ecological turns in applied ethics and in philosophy of medicine (Morar \& Skorburg 2016; Valles 2015). ${ }^{13}$

13 Thanks to Sean Valles, Eileen Amari-Vaught, Mark Navin for helpful comments on an earlier draft of this paper. Thanks to two anonymous referees for their helpful criticisms and clarifying suggestions. 


\section{REFERENCES}

Adams, F. \& Aizawa, K. 2010. "Defending the bounds of cognition”, In R. Menary (ed.), The Extended Mind. MIT Press, 67-80.

Amick, B.C. (ed.). 1995. Society and health. Oxford University Press.

Anderson, B., Ho, J., Brackett, J., Finkelstein, D., \& Laffel, L. 1997. "Parental involvement in diabetes management tasks: relationships to blood glucose monitoring adherence and metabolic control in young adolescents with insulin-dependent diabetes mellitus", The Journal of Pediatrics, 130(2): 257-265.

Arah, O. A. 2009. "On the relationship between individual and population health", Medicine, Healthcare, and Philosophy, 12:235-244.

Arseneault-Breard, J., \& al. 2012. "Combination of Lactobacillus belveticus R0052 and Bifidobacterium longum R0175 reduces post-myocardial infarction depression symptoms and restores intestinal permeability in a rat model", British Journal of Nutrition, 107:1793-1799.

Atlas, R., Rubin, C., Maloy, S., Daszak, P., Colwell, R. and Hyde, B., 2010. "One Health-attaining optimal health for people, animals, and the environment”, Microbe, 5(9):383-389.

Atlas, R. 2012. "One Health: Its Origin and Its future", Current Topics in Microbiology and Immunology, 365:1-13.

Bach-y-Rita, P., \& Kercel, S. W. 2003. "Sensory substitution and the human-machine interface", Trends in cognitive sciences, 7(12): 541-546.

Backhed, F. \& al 2004. "The Gut Microbiota as an Environmental Factor that Regulates Fat Storage." Proceedings of the National Academy of Science, 101(44): 15718-15723.

Baron, K. G., Smith, T. W., Berg, C. A., Czajkowski, L. A., Gunn, H., \& Jones, C. R. 2011. "Spousal involvement in CPAP adherence among patients with obstructive sleep apnea", Sleep and Breathing, 15(3): 525-534.

Baumeister, R. F., Bratslavsky, E., Muraven, M., \& Tice, D. M. 1998. "Ego depletion: Is the active self a limited resource?”, Journal of Personality and Social Psychology,74:1252-1265.

Bausch, D.G., Towner, J.S., Dowell, S.F., Kaducu, F., Lukwiya, M., Sanchez, A., Nichol, S.T., Ksiazek, T.G. and Rollin, P.E. 2007. "Assessment of the risk of Ebola virus transmission from bodily fluids and fomites", The Journal of infectious diseases, 196(2):S142-S147.

Beever, J. \& Morar, N. 2016. "The Porosity of Autonomy: Social and Biological Constitution of the Patient in Biomedicine", American Journal of Bioethics, 16(2): 1-12.

Beever, J. \& Morar, N. 2017. "Interconnectedness and Interdependence: Challenges for Public Health Ethics", American Journal of Bioethics, 17(9): 19-21.

Bercik, P. et al. 2011. "The intestinal microbiota affect central levels of brain-derived neurotropic factor and behavior in mice", Gastroenterology 141: 599-609.e3

Berg, C. A., Butner, J. E., Butler, J. M., King, P. S., Hughes, A. E., \& Wiebe, D. J. 2013. "Parental persuasive strategies in the face of daily problems in adolescent type 1 diabetes management", Health Psychology, 32(7):719.

Best, J. R., Goldschmidt, A. B., Mockus-Valenzuela, D. S., Stein, R. I., Epstein, L. H., \& Wilfley, D. E.2016. "Shared weight and dietary changes in parent-child dyads following family-based obesity treatment", Health Psychology, 35(1):92.

Blaser, M. 2014. Missing Microbes: How the Overuse of Antibiotics is Fueling our Modern Plagues. New York: Macmillan Publishers.

Boorse, C. 1975. "On the distinction between disease and illness", Philosophy \& Public Affairs 5(1):4968.

Boorse, C. 1977. "Health as a theoretical concept", Philosophy of Science, 44(4): 542-573. 
Boorse, C. 1997. "Rebuttal on Health”, In J.M. Humber \& al. (eds.) What is Disease?, 1-134. New York: Springer.

Boorse, C. 2014. "A second Rebuttal on Health", Journal of Medicine and Philosophy, 39(6):683-724.

Borody, T.J. and Khoruts, A. 2012. "Fecal microbiota transplantation and emerging applications", Nature reviews gastroenterology and hepatology, 9(2):88-96.

Capps, B. \& Lederman, Z. 2015. "One Health, Vaccines and Ebola: The Opportunities for Shared Benefits", Journal of Environmental and Agricultural Ethics, 28(6):1011-1032.

Carter, J. A., \& Palermos, S. O. 2016. "Is having your computer compromised a personal assault? The ethics of extended cognition", Journal of the American Philosophical Association, 2(4): 542560 .

Cash, M. 2013. "Cognition without borders: 'Third wave' socially distributed cognition and relational autonomy. Cognitive Systems Research, 25: 61-71.

Centers for Disease Control and Prevention. 2013. One Health Meetings. Available from: http://www.cdc.gov/onehealth/resources/meetings.html (accessed 09.10.17.).

Clark, A. 2017. "Andy Clark on the Extended Mind", Philosopby Bites, available at: http://philosophybites.com/2017/03/andy-clark-on-the-extended-mind.html

Clark, A. \& Chalmers, D. 1998. “The Extended Mind”, Analysis, 58(1):7-19

Clark, A. 2007a. "Re-inventing ourselves: The plasticity of embodiment, sensing, and mind:, Journal of Medicine and Philosophy, 32(3):263-282.

Clark, A. 2007b. "Soft selves and ecological control", In D. Ross, D. Spurrett, H. Kincaid, \& G.L. Stephens (eds.) Distributed cognition and the will: Individual volition and social context, 101-122. MIT Press.

Clark, A. 2010. “Memento’s Revenge: The Extended Mind, Extended,” In R Menary (ed.) The Extended Mind, 43-66. Cambridge, MA: MIT Press.

Coker, R., Rushton, J., Mounier-Jack, S., Karimuribo, E., Lutumba, P., Kambarage, D., Pfeiffer, D.U., Stärk, K. and Rweyemamu, M., 2011. "Towards a conceptual framework to support one-health research for policy on emerging zoonoses", The Lancet infectious diseases, 11(4): 326331.

Cook, R.A. et al. 2004. The Manhattan Principles on 'One World, One Health.' New York: Wildlife Conservation Society. Available at: http://www.oneworldonehealth.org (accessed December $25,2017)$.

Collins, S., Surette, M., Bercik, P. 2012. "The Interplay between the intestinal microbiota and the brain", Nature Reviews, 10:735-742.

Colizza, V., Vespignani, A.2010. “The flu fighters", Physics World, 26-30.

Costello, E.K., Stagaman, K., Dethlefsen, L., Bohannan, B.J. and Relman, D.A., 2012. "The application of ecological theory toward an understanding of the human microbiome", Science, 336(6086):1255-1262.

Hinchliffe, S. and Craddock, S., 2015. "One World One Health? Social science engagements with the one medicine agenda". Social Science \& Medicine, 129:1-4.

Cryan, J. \& Dinan, T. 2012. "Mind-altering microorganisms: the impact of the gut microbiota on brain and behavior", Nature Reviews Neuroscience, 13:701-712.

Daniels, N., 2007. Just Health: Meeting Health Needs Fairly. Cambridge: Cambridge University Press.

Dantas-Torres \& al. 2012. "Ticks and tick-borne diseases: a One Health perspective", Trends in Parasitology, 28(10):437-446

Demaio, A.R. and Rockström, J., 2015. "Human and planetary health: towards a common language", The Lancet, 386(10007):36-37. 
Degeling, C., Johnson, J., Kerridge, I. Wilson, A., Ward, M., Stewart, C. \& Gilbert, G. 2015.

"Implementing a One Health approach to emerging infectious disease: reflections on the socio-political, ethical and legal dimensions." BMC Public Health, 15(1):1307.

De Jaegher, H., Di Paolo, E., \& Gallagher, S. 2010. "Can social interaction constitute social cognition?" Trends in Cognitive Sciences, 14(10): 441-447.

Di Paolo, E. 2008. "Extended life", Topoi, 28(1): 9-21.

Di Paolo, E. 2005. "Autopoiesis, adaptivity, teleology, agency", Phenomenology and the Cognitive Sciences, 4(4):429-452.

Drigotas, S. M., Rusbult, C. E., Wieselquist, J., \& Whitton, S. W. 1999. "Close partner as sculptor of the ideal self: behavioral affirmation and the Michelangelo phenomenon", Journal of personality and social psychology, 77(2): 293-323.

Doust, J., Walker, M. J., \& Rogers, W.A.. 2017. "Current Dilemmas in Defining the Boundaries of Disease", Journal of Medicine and Philosophy, 42:350-366

Engelhardt, H.T. 1975. "The Concepts of Health and disease", in H.T. Engelhardt Jr. and S.F. Spicker (eds), Evaluation and Explanation in the Biomedical Sciences, Dordrecht: Reidel, 125-141.

Engelhardt Jr, H.T., 1976. "Ideology and etiology", The Journal of Medicine and Philosophy, 1(3):256-268.

Ereshefsky, M. 2009. "Defining 'health' and 'disease"', Studies in History and Philosophy of Biological and Biomedical Sciences, 40:221-227.

Finkel, E.J., Fitzsimons, G.M., \& van Dellen, M.R. Forthcoming. "Self-Regulation as a transactive process" In K. Vohs \& R. Baumeister (eds.) Handbook of Self-Regulation: Research, Theory, and Applications. New York: Guilford Press.

Fitzsimons, G. M., Finkel, E. J., \& van Dellen, M. R. 2015. “Transactive goal dynamics”, Psychological Review, 122(4):648-673.

Franks, M. M., Shields, C. G., Lim, E., Sands, L. P., Mobley, S., \& Boushey, C. J. (2012). I will if you will: Similarity in married partners' readiness to change health risk behaviors. Health Education \& Behavior, 39(3), 324-331.

Gallagher, S. 2013. The socially extended mind. Cognitive Systems Research, 25: 4-12.

Gareau, M. G. et al. 2011. "Bacterial infection causes stress induced memory dysfunction in mice", Gut 60: 307-317

Goosens, W., 1980, "Values, Health and Medicine", Philosophy of Science, 47: 100-115.

Gordon, J. \& Klaenhammer, T. 2011. "A rendezvous with our microbes”, Proceedings of the National Academy of Science, 108:4513-15.

Grice, E. \& Segre, J. 2012. "The Human Microbiome: Our Second Genome”, Annual Review of Genomics and Human Genetics, 13:151-170

Griffiths, P. E., \& Gray, R. D. 1994. "Developmental systems and evolutionary explanation", The Journal of Philosophy, 91(6): 277-304.

Gupta, S. \& al. 2016. "Fecal Microbiota Transplantation: in perspective", Therapeutic Advances in Gastroenterology, 9(2):229-239.

Heersmink, R. 2015. "Dimensions of Integration in Embedded and Extended Cognitive Systems", Phenomenology and the Cognitive Sciences, 13(3): 577-598.

Hehemann, J-H. et al. 2010. "Transfer of carbohydrate-active enzymes from marine bacteria to Japanese gut microbiota", Nature, 464:908-914.

Heijtz, R. D. \& al. 2011. "Normal gut microbiota modulates brain development and behavior", Proceedings of the National Academy of Science, 108(7):3047-3052.

Hemphill, R. C., Martire, L. M., Polenick, C. A., \& Stephens, M. A. P. (2016). Spouse confidence and physical function among adults with osteoarthritis: the mediating role of 
spouse responses to pain. Health Psychology, 35(10), 1059-1068.

Hinchliffe, S. 2015. "More than one world, more than one health: Re-configuring interspecies health", Social Science \& Medicine, 129:28-35.

Horton, R. \& al. 2014. "From public to planetary health", The Lancet, 383:847.

Hutchins, E. 2010. "Cognitive ecology", Topics in cognitive science, 2(4):705-715.

Ickes, W., Snyder, M., \& Garcia, S. 1997. "Personality influence on the choice of situations”, In R. Hogan, J. Johnson, \& S. Briggs (eds.), Handbook of personality psychology. New York: Academic Press, 165-195.

Jones, E.E. 1986. Interpreting interpersonal behavior: the effects of expectancies. Science, 234(4772): 41-46.

Kaira, S. \& al .2014. "The Emergence of Ebola as a Global Health Security Threat: From 'Lessons Learned' to Coordinated Multilateral Containment Efforts”, Journal of Global Infectious Diseases, $6(4): 164-177$

Kakkar, M. and Abbas, S.S., 2011. "One health: moving from concept to reality", The Lancet Infectious Diseases, 11(11):808.

Kelly C.R, et al. 2014. "Fecal microbiota transplant for treatment of Clostridium difficile infection in immunocompromised patients", American Journal of Gastroenterology, 109:1065-1071.

Kelly, C.R., Khoruts, A., Staley, C., Sadowsky, M.J., Abd, M., Alani, M., Bakow, B., Curran, P., McKenney, J., Tisch, A. and Reinert, S.E., 2016. "Effect of Fecal Microbiota Transplantation on Recurrence in Multiply Recurrent Clostridium difficile Infection: A Randomized Trial", Annals of internal medicine, 165(9): 609-616.

Kelly, C. 2013. "Fecal Microbiota Transplantation - An Old Therapy comes of Age", New England Journal of Medicine, 368(5):474-475.

Kim, K. \& Johnson, M. 2010. "Extended self: Medial prefrontal activity during transient association of self and objects", Social, Cognitive, and Affective Neuroscience 7(2):199-207.

Knight. R. 2015. Follow your Gut: The Enormous Impact of Tiny Microbes, New York: Simon \& Schuster.

Lee, L. 2017. "A Bridge Back to the Future: Public Health Ethics, Bioethics, and Environmental Ethics", The American Journal of Bioethics, 17(9): 5-12

Leroy, E.M., Kumulungui, B., Pourrut, X., Rouquet, P., Hassanin, A., Yaba, P., Délicat, A., Paweska, J.T., Gonzalez, J.P. and Swanepoel, R., 2005. "Fruit bats as reservoirs of Ebola virus", Nature, 438(7068): 575-576.

Mackenzie, J. \& al. 2013. One Health: The Human-Animal-Environment Interfaces in Emerging Infectious Diseases, New York: Springer.

MacKenzie, C., and N. Stoljar, eds. 2000. Relational autonomy. New York, NY: Oxford University Press

Mann, T., De Ridder, D., \& Fujita, K. 2013. Self-regulation of health behavior: social psychological approaches to goal setting and goal striving. Health Psychology, 32(5): 487-498.

Maravita, A. \& Iriki, A. 2004. "Tools for the body (schema)", Trends in Cognitive Sciences, 8(2):79-86.

Margolis, J., 1976. "The concept of disease", The Journal of Medicine and Philosophy, 1(3):238-255.

Marmot, M. 1998. "Improvement of social environment to improve health", The Lancet, 351:57-60.

Marmot, M. 2005. "Social determinants of health inequalities", The Lancet, 365:1099-1104.

Martz, J. M., Verette, J., Arriaga, X. B., Slovik, L. F., Cox, C. L., \& Rusbult, C. E. 1998. "Positive illusion in close relationships", Personal Relationships, 5:159-181.

May, T., Byonanebye, J. \& Meurer, J., 2017. “The Ethics of Population Health Management: Collapsing the Traditional Boundary Between Patient Care and Public Health", Population bealth management, 20(3):167-169. 
McFall-Ngai \& al. 2013. "Animals in a Bacterial World, a New Imperative for the Life Sciences." Proceedings of the National Academy of Science, 110(9): 3229-3236

McShane, K., 2004. "Ecosystem health", Environmental Ethics, 26(3):227-245.

Menary, R. 2010a. (ed.) The extended mind. MIT Press.

Menary, R. 2010b. Introduction to the special issue on 4E cognition. Phenomenology and the Cognitive Sciences, 9(4): 459-463.

Messaoudi, M. et al. 2011. "Assessment of psychotropic-like properties of a probiotic formulation (Lactobacillus helveticus R0052 and Bifidobacterium longum R0175) in rats and human subjects, British Journal of Nutrition, 105:755-764.

Mischel, W., Shoda, Y., \& Rodriguez, M. 1989. "Delay of gratification in children", Science 244(4907): 933-938.

Mischel, W. 1974. "Processes in delay of gratification”, In L, Berkowitz (ed.), Advances in experimental social psychology. New York: Academic Press, pp. 249-292.

Morar, N. \& Bohannan, B. Under Review. "A conceptual ecology of the human microbiome", available upon request.

Morar, N. \& Skorburg, J. 2016. "Toward an Ecological Bioethics”, American Journal of Bioethics, 16(5):35-37.

Nash, D. et al. 2001. "The outbreak of West Nile Virus infection in the New York City Area in 1999", The New England Journal of Medicine, 344(24): 1807-1814

Neufeld, K.M. \& al. 2010. "Reduced anxiety-like behavior and central neurochemical change in germ-free mice", Neurogastroenterology \& Motility, 23: 255-e119.

One Health Initiative Task Force: King, L.J., Anderson, L.R., Blackmore, C.G., Blackwell, M.J., Lautner, E.A., Marcus, L.C., Meyer, T.E., Monath, T.P., Nave, J.E., Ohle, J. and Pappaioanou, M., 2008. "Executive summary of the AVMA one health initiative task force report", Journal of the American Veterinary Medical Association, 233(2):259-261.

Palermos, S. O. 2014. "Loops, Constitution and Cognitive Extension", Cognitive Systems Research, 27: 25-41.

Pace, N.R. \& al. 1986. "The analysis of natural microbial populations by ribosomal RNA sequences", Advances in Microbial Ecology, 9:1-55.

Postgate, J. 2008. Microbes and Man. Cambridge: Cambridge University Press.

Rauers, A., Riediger, M., Schmiedek, F., \& Lindenberger, U. 2011. With a little help from my spouse: Does spousal collaboration compensate for the effects of cognitive aging?, Gerontology, 57(2), 161-166.

Ravel, J. \& al. 2014. "Human Microbiome Science: Vision for the Future.” Microbiome 2(2014): $1-11$.

Reich, A.D., Hansen, H.B. and Link, B.G., 2016. "Fundamental interventions: How clinicians can address the fundamental causes of disease", Journal of bioethical inquiry, 13(2):185-192.

Relman, D. 2015. "The Human Microbiome and the Future Practice of Medicine". JAMA, 314:1127-1128

Rhee, SH., Pothoulakis, C., Mayer. EA. 2009. "Principles and clinical implications of the braingut-enteric microbiota axis", Nature Reviews Gastroenterology \& Hepatology, 6(5):306314.

Rhodes, R., Gligorov, N., \& Schwab, A.P., 2013. The Human Microbiome: Ethical, Legal, and Social Concerns, Oxford: Oxford University Press.

Rock, M.J., Degeling, C. and Blue, G., 2014. "Toward stronger theory in critical public health: Insights from debates surrounding posthumanism", Critical Public Health, 24(3):337-348.

Rogers, W.A., \& Walker, M. J. 2017. “The Line-drawing Problem in Disease Definition”, Journal of Medicine and Philosophy, 42:405-423. 
Rose, G., 2001. "Sick individuals and sick populations”, International journal of epidemiology, 30(3):427432.

Rosenberg, E. and Zilber-Rosenberg, I., 2016. "Microbes drive evolution of animals and plants: the hologenome concept", MBio, 7(2):1395-15.

Rosebury, T. 1969. Life on Man. New York: Viking Press.

Rowlands, M. 2013. The New Science of the Mind: From Extended Mind to Embodied Phenomenology, MA: Massachusetts Institute of Technology Press.

Rowlands, M. 2009. "Enactivism and the extended mind," Topoi, 28(1): 53-62.

Ruger, J.P., 2004. "Ethics of the social determinants of health", Lancet, 364(9439):1092.

Rupert, R. D. 2009. Cognitive systems and the extended mind. Oxford University Press.

Rupert, R.D. 2004. "Challenges to the hypothesis of extended cognition," The Journal of philosophy 101(8): 389-428.

Saunders, L. 2000. "Virchow's contributions to veterinary medicine: Celebrated then, forgotten now", Veterinary Pathology, 37:199-207.

Scannapieco F.A. 1994. "Saliva-bacterium interactions in oral microbial ecology". Critical Review in Oral Biology and Medicine, 5(3-4):203-48.

Schlam, T. \& al. 2013. "Preschoolers' delay of gratification predicts their body mass 30 years later. Journal of Pediatrics 162(1):90-93.

Schenkman, L. 2010. “Japanese Guts are made for Sushi”, Science, Apr. 7.

Sender, R., Fuchs, S., Milo, R. 2016.” Revised Estimates for the Number of Human and Bacteria Cells in the Body", PLOS Biology, doi.org/10.1371/journal.pbio.1002533

Sonnenburg, J. 2010. “Genetic Pot Luck”, Nature, 464:837-838.

Shomaker, T., Green, E., Yandow, S. 2013. "Perspective: One Health: a compelling convergence”, Academic Medicine, 88(1):49-55.

Skorburg, J.A. 2017. Lessons and new directions for extended cognition from social and personality psychology. Philosophical Psychology, 1-20. http://dx.doi.org/10.1080/09515089.2017.1282606

Sonowal, R. \& al. 2017. "Indoles from commensal bacteria extend healthspan", Proceedings of the National Academy of Science, 114: E7506-E7515.

Sterelny, K. 2010. "Minds: Extended or scaffolded?” Phenomenology and the Cognitive Sciences, 9(4):465481.

Sutton, J., Harris, C. B., Keil, P., \& Barnier, A. J. 2010. The psychology of memory, extended cognition, and socially distributed remembering. Phenomenology and the Cognitive Sciences, 9: 521560.

Thompson, E. 2007. Mind in life: Biology, phenomenology, and the sciences of mind. Harvard University Press: Cambridge, MA.

Turnbaugh, P. \& al. 2007. "The Human Microbiome Project”, Nature, 449:804-810.

Turnbaugh, P. \& al. 2009. "A core microbiome in obese and lean twins", Nature, 457:480-485 The Human Microbiome Consortium. 2012. "A framework for microbiome research", Nature, 486:215-221

Valles, S. 2015. "Bioethics and the Framing of Climate Change's Health Risks", Bioethics, 29(5):334-341.

Varela, F.J. 1997. "Patterns of life: intertwining identity and cognition”, Brain and Cognition, 34(1):7287

Walker, M. J., \& Rogers, W.A.. 2017. "Introduction: The Boundaries of Disease”, Journal of Medicine and Philosophy, 42:343-349.

Wilson, S. J., Martire, L. M., \& Sliwinski, M. J. (2017). Daily Spousal Responsiveness Predicts Longer-Term Trajectories of Patients' Physical Function. Psychological Science, 28(6), 786-797. 
Wilson, R. A., \& Clark, A. 2009. "How to Situate Cognition: Letting Nature Take its Course", In M. Aydede \& P. Robbins (Eds.), The Cambridge Handbook of Situated Cognition. Cambridge University Press, 55-77.

Woese, C. \& Fox, G. 1977. "Phylogenetic structure of the prokaryotic domain: The primary kingdoms", Proceedings of the National Academy of Science, 74(11):5088-5090.

Wolf, M. 2005. "Is there really such a thing as "One Health"? Thinking about a more than human world from the perspective of cultural anthropology", Social Science \& Medicine, 129:511.

Zinsstag \& al. 2011. "From 'one medicine' to 'one health' and systemic approaches to health and well-being", Preventive Veterinary Medicine, 101:148-156.

Zinsstag \& al. 2015. One Health: The Theory and Practice of Integrated Health Approaches, Boston: Cabi Publishing. 